\title{
Ensino do corpo humano: mediações teatrais na formação inicial de professores - para além das partes
}

\section{Teaching the human body: theater mediations in initial teacher training - beyond the parties}

\section{Cássia Nunes Leão ${ }^{1}$; Nadia Magalhães da Silva Freitas ${ }^{2}$; Erllon Rodolfo Viegas Barata ${ }^{3}$; Nívia Magalhães da Silva Freitas ${ }^{4}$}

1 Graduada, Universidade Federal do Pará, Belém, Pará, Brasil - cassialeao_nunes@ hotmail.com,/https://orcid.org/00000002-2157-2572.

2 Doutora, Universidade Federal do Pará, Belém, Pará, Brasil - nadiamsf@ yahoo.com.br,/https://orcid.org/0000-0003-00428640 .

3 Mestrando, Universidade Federal do Pará, Belém, Pará, Brasil - erlon.rodolfo@ gmail.com,/https://orcid.org/0000-00028202-975X.

4 Doutora, Universidade Federal do Pará, Belém, Pará, Brasil - nivia.bio2015@gmail.com,/ https://orcid.org/0000-00428684.

Recebido em 23/03/2018. Publicado em Dezembro/2019

Palavras-chave:

Corpo humano.

Formação de

Professores. Ensino de

Ciências. Teatro.
Keywords:

Human Body. Teacher training. Science education. Theater.
RESUMO: O corpo tem sido objeto de estudo de diversos campos das ciências, na perspectiva de compreendê-lo em sua multidimensionalidade. Entretanto, a despeito desse fato, no ensino de ciências, ainda há uma divisão do corpo humano em "partes", cuja abordagem pauta-se nas perspectivas anatômicas e fisiológicas. A abordagem do corpo humano requer, para além de sua incidência sobre a dimensão biológica, a consideração dos acontecimentos contemporâneos. Buscamos, por meio da materialidade mediadora do teatro (produção de esquetes teatrais), compreender em que termos uma experiência formativa, envolvendo o tema corpo humano, contribui para a apreensão crítica e reflexiva de uma das dimensões que o constituem - a dimensão social, precisamente na abordagem do tema obesidade, como uma cena social dos tempos atuais. Adotamos a pesquisa-formação, de natureza qualitativa, como uma das dimensões da pesquisa narrativa. Os sujeitos da pesquisa estavam representados por três licenciandas do Curso de Licenciatura Integrada em Educação em Ciências, Matemática e Linguagens, da Universidade Federal do Pará. As narrativas das três futuras professoras foram submetidas à análise textual discursiva. Os resultados da experiência revelam que as licenciandas construíram um discurso cênico com criticidade e criatividade, precisamente ao experimentarem um modo próprio de problematização dos aspectos associados à obesidade. Por sua vez, as licenciandas colocaram em evidencia o cotidiano da sociedade, associado aos tempos modernos, notadamente no que diz respeito à celeridade da vida atual na configuração de comportamentos alimentares obesogênico, afastando-se da compreensão do corpo humano desvinculado da sociedade, com todos os seus enredos circunscritos.

ABSTRACT: The body has been object of study of diverse fields of sciences, with the perspective of understanding it in its multidimensionality. Despite of this fact, in science teaching there is still a division of the human body into "parts", based on the anatomical and physiological perspectives. The approach of the human body requires, in addition to its incidence on the biological dimension, the consideration of contemporary events. Through the theater (the production of theatrical sketches), we seek to understand in what terms a formative experience, involving the theme human body and health, contribute to the critical and reflexive apprehension of one of the 
dimensions that constitute it - the social dimension, precisely in the approach to the subject obesity, as a social scene of the present times. Qualitative approach, represented by narrative research, in the form of research-training, constituted the methodological option. The subjects of the research were represented by three undergraduate students of the Licenciatura Integrada em Educação em Ciências, Matemática e Linguagens, of Instituto de Educação Matemática e Científica, of Universidade Federal do Pará. The narratives were submitted to discursive textual analysis. The formative experience show that the undergraduate students constructed a scenic discourse with criticality and creativity and a proper way of problematizing aspects associated with obesity. They highlighted the daily life of society, with regard to the celerity of the present life in the configuration of obesogenic feeding behaviors, away from the understanding of the human body unrelated to society, with all its entanglements circumscribed.

\section{INTRODUÇÃO}

O corpo humano tem se constituído objeto de estudo de diversos campos do conhecimento, o que tem levado a uma profusão de compreensões (MILSTEIN; MENDES, 2010; TALOMONI; BERTOLLI FILHO, 2005; 2009). Entretanto, a despeito dessas múltiplas inserções, o ensino de Ciências ainda tem valorizado a dimensão biológica do corpo humano, ao considerarmos que, historicamente, “[...] o corpo foi interpretado sob uma ótica dualista, mecanicista e biologicista" (MACHADO; BARRETO, 2013, p. 1). Nesse sentido, o corpo humano quase nunca é tratado “[...] como um sistema, mas nos moldes cartesianos: seccionado para que através do estudo de suas partes os/as alunos/as possam construir o todo. Aliás, um pretenso todo que nunca é retomado na escola" (SANTOS, 2002, p.102).

Para Mendes e Nóbrega (2004, p.125),

O corpo humano, ao ser comparado com uma máquina hidráulica, recebe uma educação que o considera apenas em seu aspecto mecânico, sem vontade própria, sem desejos e sem o reconhecimento da intencionalidade do movimento humano, o qual é explicado através da mera reação a estímulos externos, sem qualquer relação com a subjetividade.

Ao compreendermos o corpo humano como uma mera máquina, com componentes idênticos que a constituem, sem expressão ou individualidade, estamos negando toda a singularidade que caracteriza os seres humanos e, esvaziam-se, então, todas as possibilidades de consideração do corpo humano como um "objeto" de multidimensões "[...] a partir das quais ele pode ser situado e melhor compreendido [...]" (TALOMONI; BERTOLLI FILHO, 2005 , p. 1). Há que se considerar que o “[...] corpo é repleto de multiplicidades. Ele é ao mesmo tempo social, psicológico, biológico e transcendente" (RIOS, 2015, p. 2).

Temos que reconhecer que a educação ainda hoje recebe fortes influências do pensamento cartesiano e um dos desdobramentos desta perspectiva materializa-se, no ensino do corpo humano, segundo "suas partes" (RAMOS; FONSECA: GALIETA, 2018). Para Trivelato (2005, p. 122 apud RAMOS; FONSECA; GALIETA, 2018, p. 310), 


\begin{abstract}
Mesmo sem avançar num estudo da história da ciência com respeito a esse tema, é fácil perceber que o conhecimento sobre corpo humano se origina na divisão ou separação de partes anatômicas e sistemas fisiológicos. O conhecimento que acumulamos até hoje é fruto dessa abordagem, e seria ilusão pensar que na escola básica o corpo humano se constituísse de maneira diferente, à revelia da produção científica.
\end{abstract}

Entretanto, evidencia-se, por outro lado, abordagens ao corpo humano que tem se constituído "[...] como aquela que abrange o corpo para além de perspectivas puramente biológicas e fisiológicas [...]" (VIANNAY; SELLES, 2016, p. 3095), contribuindo para uma visão do corpo humano em uma perspectiva multidimensional.

Neste ponto, podemos referir que aprender e ensinar Ciências não se limita, única e exclusivamente, a abordagens de conteúdos curriculares. Há que se considerar as relações que se estabelecem entre conhecimento e situações cotidianas. É nesse sentido, que evocamos a arte, ao reconhecer que ela permite ao indivíduo alargar sua capacidade de criar, de expressar seu eu, de compreender criticamente as situações cotidianas e, assim, propor as transformações necessárias. Assim sendo, corroboramos com Vasconcellos (2006), ao ponderar que as produções da ciência e da arte representam extensões das nossas vivências e experiências, constituindo-se formas de conhecimento.

A arte produz espaços de reflexão/ação, colaborando com a apreensão do saber com sensibilidade e criticidade (VASCONCELLOS, 2006). Concordamos com Freitas (2017, p. 29), ao afirmar que a arte instiga

[...] a dimensão sensível do humano [...] colabora para inserção do ser humano no mundo com qualidade social, justamente na apreensão sensível das múltiplas questões (social, econômica, política, ambiental, ética etc.) que se afiguram na atual sociedade, em processo de intensa transformação [...].

É nesse sentido, de consideração da arte, precisamente do teatro como importante estratégia de ensino e, ainda, do ensino do corpo humano como "objeto" multidimensional, que o presente trabalho objetivou compreender em que termos uma experiência formativa, envolvendo o tema corpo humano e saúde, tendo o teatro como materialidade mediadora do aprender e do ensinar ciências, contribui para a apreensão crítica e reflexiva da sua dimensão social, especificamente na abordagem do tema obesidade, como uma cena social dos tempos atuais.

\title{
O ENREDO DA PESQUISA-FORMAÇÃO
}

A pesquisa configurou-se como de natureza qualitativa (MINAYO, 2016). Adotamos a pesquisa-formação, uma das dimensões da pesquisa narrativa. Nos termos de Josso (2010), a pesquisa-formação fundamenta-se na concepção de que os processos formativos abrangem uma dimensão de conhecimento; assim, quem dele participa é capaz de narrá-los, tanto em uma construção individual como coletiva, colaborando para a formação dos indivíduos, à 
medida que se configura, no espaço de sala de aula, um ambiente onde os indivíduos são capazes de construir aprendizagens tanto interpretativas como reflexivas.

A pesquisa ocorreu no contexto do desenvolvimento do tema ${ }^{1}$ Alfabetização e Letramento em Ciências e Matemática I - Corpo Humano e Saúde, do Curso de Licenciatura Integrada em Educação em Ciências, Matemática e Linguagens, da Universidade Federal do Pará. Na abordagem metodológica da referida temática, trabalhamos "corpo humano e saúde" sob a perspectiva biológica, como constante na sua ementa ${ }^{2}$. Entretanto, para escapar desse viés unicamente biologicista dos conteúdos, experimentamos a produção de conhecimentos, partir da materialidade mediadora do teatro - uma experimentação estética, em vinculação a uma abordagem socioambiental, ou seja, aquela que relaciona o corpo humano aos meios social e ambiental (MOREIRA, VILELA; SELLES, 2015). Assim, propusemos a produção de esquetes teatrais, envolvendo quatro eixos: como e quando nasce o corpo, o corpo crescendo, o corpo adulto e o corpo idoso.

Trazemos para este artigo, a análise do esquete teatral que tratou do tema obesidade como uma dimensão social do eixo "corpo adulto", o qual foi desenvolvido por três licenciandas, identificadas, neste texto, pelas três primeiras letras do nome, acrescidas das primeiras letras dos sobrenomes. Cabe destacar, neste ponto, que os discentes participantes da pesquisa assinaram o Termo de Consentimento Livre e Esclarecido (TCLE). Nele constavam objetivos, metodologia, benefícios e possíveis riscos da pesquisa para os mesmos. Também realizamos os devidos esclarecimentos sobre dúvidas da pesquisa. As discentes autorizaram a divulgação das suas falas e imagens.

Os instrumentos de coleta de dados se constituíram em diários de formação, texto do esquete teatral, questionário e entrevista. As notações dos vários momentos do processo de pesquisa-formação foram realizadas em diário de bordo dos pesquisadores, a partir de observações diretas, além dos elementos da videogravação, relativas às apresentações dos esquetes teatrais.

As falas das três futuras professoras foram submetidas à Análise Textual Discursiva (ATD), nos termos de Moraes e Galiazzi (2013). A ATD é “[...] concebida como um processo auto-organizado de produção de novas compreensões em relação aos fenômenos que

\footnotetext{
${ }^{1}$ O Curso em que a pesquisa ocorreu está organizado por eixos temáticos, temas e assuntos, numa perspectiva interdisciplinar, opondo-se à estrutura disciplinar propriamente dita, e ocupa-se com o letramento científico, matemático, digital e na língua materna.

${ }^{2}$ Corpo humano e saúde: estudo do desenvolvimento humano do ponto de vista biológico, salientando-se os aspectos nutricionais e de higiene, incluindo noções anatômicas e fisiológicas do corpo humano (circulação, respiração, digestão etc.); considerações gerais relacionadas a doenças causadas por agentes infecciosos e parasitários; reprodução e hereditariedade; práticas de laboratório em biologia celular (esfregaço bucal/ visualização de tecidos humanos).
} 
examina” (MORAES; GALIAZZI, 2013, p. 43). Os textos, no nosso caso, os textos de campo, submetidos à análise são denominados corpus, assim caracterizados:

[...] produções que expressão discursos sobre diferentes fenômenos e que podem ser lidos, descritos e interpretados, correspondendo a uma multiplicidade de sentidos que a partir deles podem ser construídos (MORAES; GALIAZZI, 2013, p. 16).

$\mathrm{Na}$ análise dos dados, são retirados do corpus os elementos que serão empregadas na construção de um novo texto, nomeado de metatexto, que dizem respeito aos resultados da análise. Na construção dos metatextos, é necessário extrair falas de trechos do material empírico, denominados de interlocuções empíricas e, em associação com as interlocuções teóricas, representadas pelas manifestações de autores que tratam da temática, compor os diálogos (MORAES; GALIAZZI, 2013). Nesse contexto, o metatexto representa o esforço do pesquisador em elucidar a compreensão que se mostra como resultado deste novo arranjo de elementos produzidos na construção do metatexto (MORAES; GALIAZZI, 2013).

\section{OBESIDADE: UMA DIMENSÃO DA CENA SOCIAL}

A obesidade, doença crônica não transmissível, é consequência de um balanço energético positivo, resultando em um acúmulo excessivo de gordura no tecido adiposo no organismo e, tal condição, tem sido avaliada como um dos maiores problemas de saúde pública, principalmente porque existe uma estreita relação com diversos agravos à saúde (diabetes, doenças cardiovasculares, hipertensão, entre outras); e, ainda, evidencia-se rápido crescimento na sua prevalência, entre outros aspectos (FARIAS JÚNIOR; SILVA, 2008; OMS, 2000). A obesidade se mostra presente tanto em países desenvolvidos como naqueles considerados em desenvolvimento (países emergentes), tanto na população jovem como na adulta (FERNANDES, 2008; RECH et al., 2010).

Nos últimos anos, no Brasil, evidenciaram-se modificações no perfil nutricional, caracterizada pela redução da prevalência de desnutrição e aumento da prevalência da obesidade, caracterizando a transição nutricional (RECH et al., 2010), nos seguintes termos:

[...] marcante aumento na prevalência de obesidade, consolidando-se como o agravo nutricional mais importante, sendo associado a uma alta incidência de doenças crônicas não transmissíveis, como diabetes e doenças cardiovasculares. Alterações no estilo de vida, como a má-alimentação e redução no gasto calórico diário são os principais fatores que explicam o crescimento da obesidade (SOUZA, 2010).

Assim, podemos apresentar dois aspectos, a título de exemplificação, que tentam explicar tal fenômeno: (1) transição de uma sociedade agrária para urbana e industrial, acompanhada por diversas mudanças, entre elas mudanças nos hábitos alimentares; (2) entrada da mulher no mercado de trabalho e, neste caso, a condição da mulher como "dona de casa", responsável pela elaboração da alimentação da família, já não se mostra uma constante, levando, por sua vez, a utilização de alimentos industrializados ou mesmo a realização das 
refeições fora do lar, aderindo aos restaurantes, pensões e fast-foods (BATISTA FILHO; RISSIN, 2003; MENDONÇA; ANJOS, 2004).

De acordo com pesquisas nacionais recentes, evidencia-se que o padrão alimentar caracteriza-se pelo elevado percentual de consumo de alimentos ricos em açúcar, gorduras saturadas, trans e sal e, ainda, pelo baixo consumo de carboidratos complexos e fibras (IBGE, 2011). No processo de evolução desse padrão de consumo da população brasileira (entre as décadas de 1970 e 2009), evidenciam-se as seguintes tendências: aumento do consumo de alimentos ultraprocessados (biscoitos, embutidos, refrigerantes, refeições prontas), estabilização do consumo de frutas e hortaliças, correspondente a menos da metade da recomendação de consumo, e redução de consumo de alimentos básicos como ovos, gordura animal, peixe, leguminosas, raízes e tubérculos e arroz (IBGE, 2011).

Podemos referir que a consolidação dessas modificações na ingestão alimentar, é resultado, principalmente, de transformações econômicas, sociais, demográficas. Nesse sentido, colaboram a “[...] globalização, o marketing exacerbado de alimentos processados, o consumismo, a necessidade de prazeres rápidos e respostas imediatas contribuem para o aparecimento da obesidade como uma questão social” (BRASIL, 2014, p. 20). Assim, podemos evidenciar que a obesidade “[...] envolve complexa relação entre corpo-saúdealimento e sociedade [...]" (BRASIL, 2014, p. 20).

Assim, considerando as questões acima arroladas, podemos compreender as justificativas dos sujeitos da pesquisa, com relação à escolha do tema "Obesidade". Vejamos então:

[...] a gente escolheu por uma questão de, enfim, atualmente é uma doença que é muito frequente, inclusive em crianças, as crianças já são doentes já, já tem doenças que antes a gente só via em adultos. Então, a gente escolheu o tema obesidade porque a gente achou interessante justamente por isso, porque crianças já estão incluídas nesse contexto (ANA-C.S.S.);

[...] o nosso [tema] era o corpo adulto [...] a gente tava pensando mais no conteúdo [...]. Então, a gente meio que fixou sobre o que a gente tava estudando e o que tava remetendo a isso, então o corpo humano, tem a alimentação e dentro da alimentação a gente começou a pensar e então surgiu o nosso tema [obesidade] de certa forma, ai depois a gente foi discutir um pouco mais o porquê mesmo, foi o que ela [ANA-C.S.S.] tava falando sobre a parte mais social mesmo [...] (KAR- C.S);

[...] poderíamos dizer que há uma epidemia de obesidade que vem atingindo as crianças [...] por causa do cotidiano, hoje tudo é bem corrido, tem que ser tudo muito rápido, muito instantâneo [...] nessa correria não dá tempo de fazer uma comida saudável em casa. Então você vai no rápido, mesmo que você vá no restaurante entre você ir no restaurante e comer uma comida bonitinha ou ir no fast-food que é mais rápido até mesmo de se comer, você vai preferir ir num fast-food pra comer um hambúrguer. Devido há esse tempo corrido e aí isso vai gerando essa obesidade porque junto com isso tem o sedentarismo que as pessoas não têm mais tempo de ficar numa atividade física [...] (ISA- M. M.).

Corroborando com as licenciandas (sujeitos da pesquisa), podemos ponderar que a obesidade vem aumentando e é considerada uma epidemia mundial que atinge diferentes faixas etárias, classes sociais, sexos e, em particular, crianças (CORSO et al., 2012; 
AZAMBUJA et al., 2013). Nesse contexto, a prevalência de sobrepeso e de obesidade na infância no Brasil é preocupante (ANTUNES, 2008).

Segundo Popkin (2008), evidencia-se o engordamento da humanidade, fato atribuído à globalização que generalizou consumo de alimentos sob a inspiração do modelo dos fastfoods. Em seus estudos, Jeffery et al. (2006) relatam que a frequência com que as pessoas referem alimentar-se em restaurantes do tipo fast food está associada ao maior peso e hábitos alimentares menos saudáveis. Por outro lado, a perda inadequada de calorias pela atividade física reduzida é, também, contribuinte para o quadro (FERNANDES et al., 2008). Esses dois aspectos configuram o estilo de vida ocidental contemporâneo.

Em realidade, estamos frente ao seguinte paradoxo:

A sociedade de consumo disponibiliza diferentes oportunidades (mercadorias) que colaboram para a 'criação' do obeso, ao mesmo tempo, a obesidade é tratada como 'doença' que deve ser combatida. Assim, novas mercadorias são oferecidas aos indivíduos para se prevenirem destes 'riscos fabricados (GOMES, 2006, p. 51).

De todo modo, estamos subsumidos à lógica de consumo capitalista, ou seja, as práticas alimentares “[...] têm se tornado cada vez mais influenciadas pela economia de mercado, que tende a desmerecer esse valor simbólico dos rituais alimentares e dos costumes em função da lucratividade" (ROIZMAN, 2011, p. 32). Nesse contexto, podemos destacar o seguinte:

[...] esse 'hedonismo alimentar' coabita com os imperativos de saúde que tendem a limitar o gozo da ingestão de alimentos. Essa contradição é um indício de que a lucratividade inerente ao modelo capitalista é o alicerce de práticas e incentivos amplamente diversos, se não opostos (ROIZMAN, 2011, p. 32).

Ampliando as suas justificativas, as licenciandas assim se manifestaram:

[...] se a vida dos pais é corrida é lógico que eles vão facilitar a vida do filho, ao invés de fazer alguma coisa eu compro né? Vou ali no supermercado compro uma coisa já pronta, então eu acho que vai acostumando à criança a desde cedo a tá com aquela coisa de pensar numa coisa mais rápido, mais prático do que ter essa coisa do mais elaborado [...] o que facilita a criança ir crescendo nessa coisa da cabeça de ir nas coisas mais fácies (KAR- C. S.);

Tudo é um hábito né? Assim pra você criar um hábito saudável você tem que ter uma rotina e desde cedo né? Então, pra criar um hábito não saudável também é uma rotina. Então, querendo ou não, quando a gente falou que é algo rotineiro porque ela nunca tem tempo pra fazer nada, então se cria um hábito se cria uma rotina, a pessoa se acomoda naquela rotina [...]. Então eu acho que também é por isso essa epidemia [obesidade] vem crescendo [...] (ISA- M. M.);

[...] [A obesidade] não está somente relacionada à alimentação, existe também a questão da genética, a gente falou inclusive disso, é as causas da obesidade né? (ANA- C. S. S.).

De fato, a atual sociedade capitalista aderiu a "[...] uma série de valores-base [...] padronização, massificação, mecanização, mercantilização e, certamente, a aceleração" (BAUER; PANOSSO NETTO; TRIGO, 2015, p. 3, destaque nosso) e, neste contexto, “[...] com a falta de tempo, com a conveniência e com a acessibilidade, deparamo-nos com um 
setor de alimentação de comida rápida em constante crescimento [...] [assim] percebe-se a importância dos fatores ambientais na obesidade" (SOUZA; OLIVEIRA, 2008, p. 170).

Por sua vez, podemos avaliar que a inadequação da dieta presente na dinâmica familiar é, também, fator que pode acarretar à obesidade (OTTO; RIBEIRO, 2012). Reconhecemos, assim como as licenciandas, que o "[...] modo de viver da sociedade moderna tem determinado um padrão alimentar que, aliado ao sedentarismo, em geral não é favorável à saúde da população" (BRASIL, 2014, p. 15).

A causa da obesidade é complexa. Nesse sentido, estudos epidemiológicos, genéticos e moleculares, em muitas populações do mundo, sugerem que há pessoas que são mais suscetíveis ao aumento de peso e ao desenvolvimento da obesidade do que outras (OMS, 2000). As diferenças de suscetibilidade estão associadas aos fatores genéticos, por exemplo, como apontado por uma das licenciandas (ANA- C. S. S.).

Temos a destacar, que a prevalência mundial da obesidade, atingindo principalmente crianças e adolescentes, vem aumentando rapidamente nas últimas décadas, constituindo-se uma questão de saúde pública global - um problema social (BRASIL, 2014). Assim sendo, as licenciandas, ao considerarem o tema obesidade, ponderaram sobre a urgência do tema e sua relevância social para o ensino de ciências.

\section{SEU GORDONILDO: UM PERSONAGEM QUE PROBLEMATIZA HÁBITOS E CONSUMO ALIMENTARES CONTEMPORÂNEOS}

$\mathrm{Na}$ abordagem à obesidade, precisamente na sua problematização, as licenciandas trouxeram para a cena de sala de aula um esquete teatral cujo personagem principal era o "Seu Gordonildo" (nomeação que expressa seu quadro de obesidade), que na saída para o almoço se depara com as "chamadas" relativas à oferta de refeições. Inquiridas sobre a nomeação do personagem, se a mesma constituía-se o início da problematização, destacamos a fala de duas discentes, que expressam o sentido do nome conferido ao personagem, a saber:

[...] refletiu muito bem o que a gente queria, foi esse o propósito, assim ali, tava falando de uma pessoa que já estava num estado muito crítico, não tinha uma saúde muito boa, a gente falando na introdução sobre a vida corrida dele, que a pessoa já tava saindo do trabalho, tava pensando em comer e tava precisando voltar, então, acho que refletiu bastante que é o que a gente queria tá dando uma explicação maior em relação ao processo e tudo mais [...] (KAR- C. S.);

[...] em relação ao nome, tem aquele rotulo né do gordo, sofre aquele preconceito [...] o ponto de referência, é isso, você nunca fala, apesar de eu saber [referindo-se a uma das licenciandas], por exemplo, ela é negra, ela é do cabelo cacheado e tal, mas qual seria o ponto de referência? Tem essa cultura, eu não ia dizer: ah, perto daquela morena, perto daquela mulher do cabelo cacheado, não! Eu ia dizer perto daquela gordinha, então eu acho que o nome também meio que tem esse propósito, pra titular que ele era uma pessoa obesa [...] (ISA- M. M.). 
Assim, no desenrolar do esquete teatral aparece, inicialmente, a figura da narradora com a seguinte fala:

Em uma segunda-feira, em um dia bem agitado, em pleno horário de almoço, Seu Gordonildo sai do trabalho em busca de um almoço barato e prático. Enquanto anda pela rua observa as sugestões (KAR- C. S.).

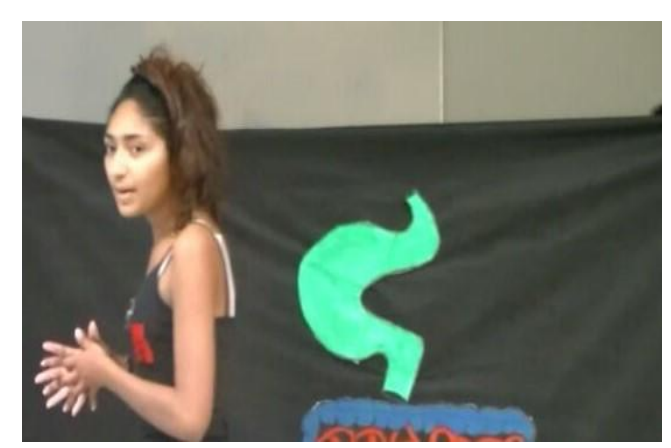

Foto 1- Narradora iniciando o esquete

Fonte: Os autores

Em um segundo momento, entram em cena os comerciantes, com suas ofertas:

X-Tudão por apenas $\mathrm{R} \$ 5,00$ ! (Isa- M. M);

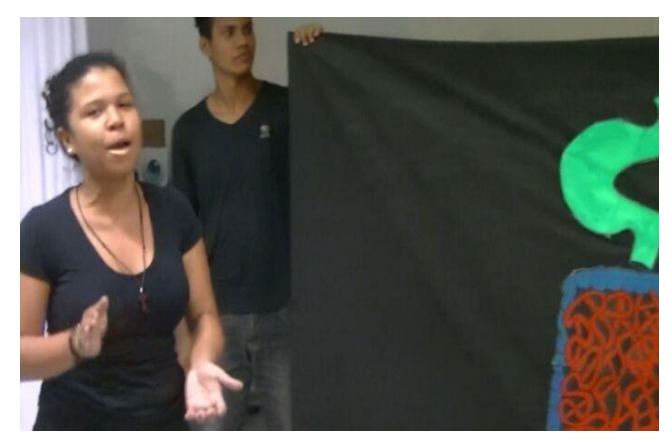

Foto 2 - Primeira Comerciante

Fonte: Os autores

Olha a coxinha, 3 por $\mathrm{R} \$ 5,00$ ! O completo é $R \$ 3,50$ [...] (ANA- C.S.S.).

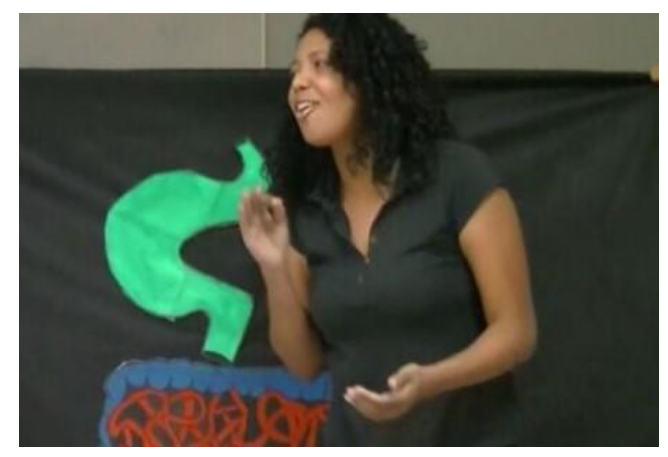

Foto 3- Segunda Comerciante

Fonte: Os autores 
Note-se aqui, que o Sr Gordonildo não nos parece ser um corpo com suas partes, propriamente dito, mas um personagem humano inserido na cena social contemporânea, marcada pela exiguidade do tempo e alheio às possibilidades de escolha refletida, dado o cenário acelerado da vida moderna.

$\mathrm{Na}$ continuidade, reaparece a narradora que assim se manifesta:

Enquanto o homem mastiga, o alimento começa o seu percurso natural. Primeiramente, ele chega à boca onde se encontra os dentes, a língua e suas papilas que podem detectar o sabor salgado e doce. (KAR- C. S.).

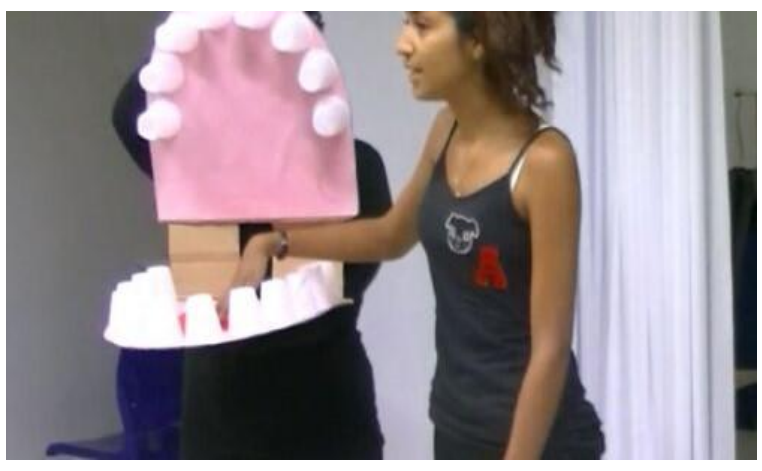

Foto 4- Narradora mostrando a boca, suas estruturas e funções

Fonte: Os autores

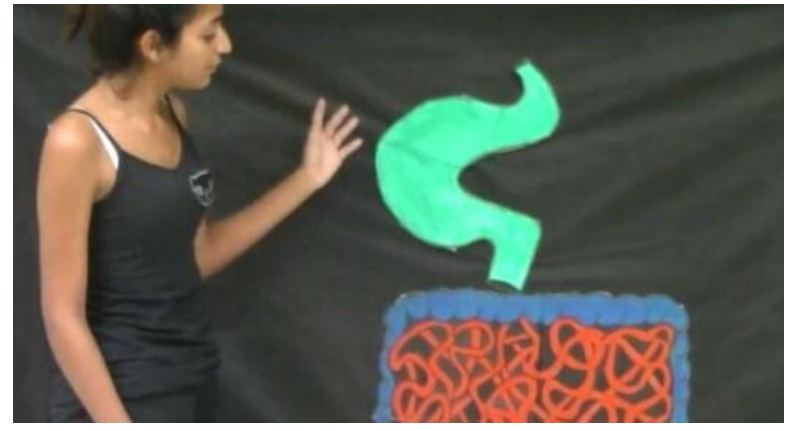

Foto 5 Narradora falando sobre o caminho que o alimento percorre no sistema digestório

Fonte: Os autores

Observamos nessa narração, que a licencianda introduz alguns aspectos relativos ao processo digestório, com as estruturas e os órgãos envolvidos. Em continuação, a narradora chama a atenção para o que ocorrerá em seguida: "Enquanto isso, dentro do Seu Gordonildo..." (KAR-C. S.), "indicando" o início do enredo teatral, propriamente dito.

Nesse momento, processa-se um diálogo entre os ingredientes do sanduíche (Isa- M. M., no papel do "pão"; Kar- C. S., no papel da "carne"; Ana- C. S. S., no papel da "salada"), conforme roteiro e o próprio esquete teatral, qual seja:

Pão: Fala rapaziada, o pãozinho está na área cheio de energia para dar.

Carne: Ai, o que é isso melecado?

Salada: Isso é a saliva, ela lubrifica facilitando a mastigação, a formação do bolo alimentar.

Pão: Hum... Então diz aí o que está nos furando? 
Salada: Os dentes, ora essa, parece que nunca escutaram falar sobre eles?

Pão: Ai, ai, isso dói!

Carne: Ai! Sai de cima de mim, está me apertando.

Salada: Claro que está apertado, olha para você! Já eu sou Fit.

Carne: Me segura, me segura, eu bater nessa magrela metida.

Pão: Ei, parem de brigar, olha, estamos caiiiindooo...

Todos: Aaaaaaaaaah...

Pão: Que lugar é esse, que apertado, aff!

Carne: Está reclamando de quê? Eu fico sendo apertado o tempo todo.

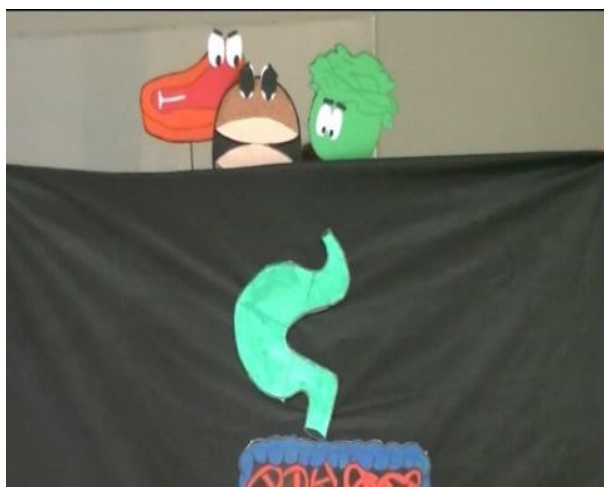

Foto 6- Diálogo entre os ingredientes de um sanduíche

Fonte: Os autores

Salada: Esse lugar é o esôfago e nos leva até o estômago.

Carne: Ninguém te perguntou.

Salada: Ai gente, o importante é a gente estar sendo ingerido e alimento alguém.

Carne: Ninguém te perguntou. Mas, quer saber, pensando por esse lado, eu sou muito gostosa, todos querem me provar, eu adoro ser querida. Mil beijos salada.

Pão: Galera, isso nem importa mais, não estão percebendo que estamos ficando 'juntinhos', não consigo nem saber onde está meu pé.

Carne: Pão, tu não tens pé.

Pão: Aaah, éee ... Ai sim, gostei daqui, é bem maior.

Carne: Bem maior! Tu já percebeste que estamos dividindo o mesmo espaço.

Pão: Galerinha, olha que legal, eu estou ficando magrinho.

Carne: O que está acontecendo, estamos ficando menores?

Salada: Dãn, é que o estômago tem um teor de acidez muito grande, sendo assim, ele leva só o necessário para o resto do percurso.

Carne: Não te perguntei, foi uma retórica, sua enxerida. Estamos ficando menores, estou odiando ficar cada vez mais perto de vocês.

Pão: Eu estou adorando me ver cada vez mais magro.

Salada: Pelo visto vocês realmente não sabem o que acontece com a gente aqui né!?

Carne: Não, e não queremos saber, e temos raiva de quem sabe.

Salada: Bom, estamos no intestino delgado, e pelo o que eu já escutei falar, ele deve absorver os nutrientes do alimento e, neste caso, nós somos o alimento. Entenderam?

Pão: Isso quer dizer o que?

Carne: Ela quer dizer que somos importantes, mas isso eu sempre soube.

Salada: Você está certa, porém, depois que já absorvido tudo o que é necessário de nós, somos descartados.

Carne: Quê? Como assim? Quer dizer que os humanos se alimentam de nós, nos usam até ficarmos sem quase nada, e depois nos descartam?

Salada: Sim.

Carne: Ah é, beleza então, eu quero sair daqui agora, não vou deixar ninguém tirar mais nada de mim.

Carne: Me tirem daqui AGORAAAAA. AAAAAAAAAAAAAAAH...

Carne: Não me segura, não me segura. Me segura pão (sussurro), eu vou sair daqui.

Salada: haha, se acalme, nós vamos sair daqui, não se preocupe. 
Pão: Ah Cara, que chato, estou entediado.

Salada: Somos dois.

Carne: Somos três. Ei, salada, Dra. Sabe tudo, quanto tempo mais vamos ter que esperar?

Salada: Depende, normalmente entre 24 e $72 \mathrm{~h}$, se dermos sorte do cara que nos ingeriu ter um intestino funcionando normalmente, mas como estamos já no estágio final, já já vamos sair.

Pão: Como assim estágio final?

Salada: Estamos no intestino grosso, onde ficam os alimentos não digeríveis e as fezes a serem jogadas fora.

Pão: Fezes? O que são?

Salada: Somos nós, detritos inúteis a serem descartados.

Carne: Opa, opa, opa. Você está me chamando de inútil?

Carne: Garota, tu vai ver quem é a inútil aqui quando euu... ei, que isso?

Pão: Estamos apertados demais

Salada: Se preparem, é agora, vamos sair daqui

Salada: 1, 2, 3 e jáaaaaaaaaaa

Carne: (splash) Só isso? Já acabou?

Salada: Estão todos bem?

Todos: Sim.

Carne: Ei, o que é isso atrás de você pão?

Milho: Faaaaalê, um salve só pra quem está inteirão!

Milho: Um forte abraço e falôou!

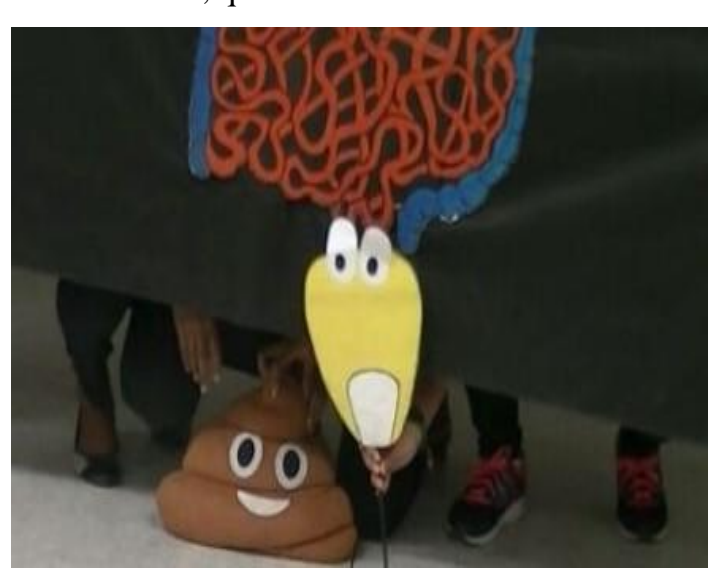

Foto 7- Finalização do esquete

Fonte: Os autores

Podemos destacar que as discentes, ao desenvolverem o esquete teatral, preocuparam-se com os conhecimentos necessários ao entendimento do processo digestório, ao mesmo tempo em que fizeram referência à função dos alimentos, especificamente do carboidrato, representado pelo pão, no que se refere ao fornecimento de energia para o organismo. Também, o uso do termo Fit (abreviação de Fitness ${ }^{3}$ ) remete para a consideração dos alimentos saudáveis, como, por exemplo, a alface. Por sua vez, indicam o milho como fonte de fibras, as quais se constituem resíduos de célula vegetal não digerível no processo digestório (FOOD INGREDIENTS BRASIL, 2008).

Indagadas sobre a intenção de utilização de um diálogo, entre os ingredientes de um sanduíche, para a problematização do tema obesidade, as discentes assim falaram:

[...] no início a gente pensou em conversar porque iria ocorrer uma batalha entre aspas, entre alimentação saudável e não saudável e no hamburg [sanduíche] a gente encontra a salada, apesar de ser só um alfacezinha, mas tá lá né a salada e tem a carne que é uma proteína boa só que aí em compensação do outro lado tem o cheddar [queijo] que é rico em gordura e tem o pão nada de leve, o pão, o bacon, a gente analisou tudo isso pensando nesse confronto digamos assim que o alimento saudável ia ter sua posição e o alimento não saudável iria colocar sua posição. Então, eu acho que é mais ou menos por isso que a gente pensou no hamburg [sanduíche], que é o que se come muito também né nos fast-foods [...] (ISA- M. M.);

\footnotetext{
${ }^{3}$ Refere-se à boa condição física, na língua inglesa. 
A gente também teve o cuidado de pensar a gente ah não, vai ser sanduíche, a depois a gente parou e pensou e refletiu até um pouco mais [...] a gente tava trazendo uma realidade talvez só de uma classe, foi que a gente pensou nuns lanches mais elaborados aí quando a gente pensou porque não um lanche de rua? Aquele de esquina, foi que a gente pensou num lanche menos assim, ah lá do lado, a gente pensou no milho ai a gente começou a pensar em outras coisas e foi mudando um pouco [...] bora abrir e pensar um pouco mais ah aquele lanche lá da rua correndo assim ah quero lanchar rápido aqui no canto tem um lanche a gente foi mais ou menos enquadrando uma coisa na outra (KAR- C. S.);

E também nessa ideia também a gente conseguiu utilizar ela porque acabou que cada alimento, tipo assim, disse qual era seu benefício, seu ganho e tudo mais pra alimentação pro corpo humano e tudo mais, então, eu acho que as duas coisas juntaram e tal sobre alimentação saudável e não saudável porque fazer o diálogo entre eles, pra que cada um pudesse realmente assim ah eu proporciono isso pro corpo, eu trago esse benefício, enfim, eu dou energia, eu dou vitaminas e tal a gente pensou no diálogo entre os alimentos por isso também (ANA- C. S. S.).

A proposição de um confronto entre os ingredientes do sanduíche, no que diz respeito a sua qualidade alimentar, revela a necessidade de superação de práticas alimentares massificadas, decorrentes do modelo urbano-industrial de alimentação e consideração da obesidade como reflexo deste estado de coisas.

Ao considerarmos que a sociedade atual apresenta um consumo alimentar obesogênico, ou seja, favorável ao desenvolvimento da obesidade, faz-se necessário que, no ambiente de sala de aula, tenhamos a preocupação em destacar práticas e comportamentos que colaborem para o desenvolvimento e a manutenção dessa condição. É nesse contexto, que ao ensino de ciências cabe fornecer conhecimentos necessários para escolhas mais saudáveis e, assim, contribuir para a educação nutricional.

\section{O TEATRO COMO CAMPO DIALÓGICO NA FORMAÇÃO INICIAL DE PROFESSORES QUE ENSINAM CIÊNCIAS: CENÁRIOS DE UMA EXPERIÊNCIA}

Os desafios que hoje se apresentam a formação de professores que ensinam Ciências, no que se refere à compreensão efetiva e significativa dos aspectos relacionados ao corpo humano e a saúde, mostram-se relevantes, ao considerarmos a necessidade do estabelecimento de uma nova/outra identidade para o seu ensino. Nesse sentido, buscamos na materialidade mediadora do teatro essa renovação.

Assim considerando, experimentamos a abordagem ao corpo humano, para além das partes, destacando as preocupações contemporâneas do campo da saúde. Propusemos aos discentes a elaboração de esquetes teatrais para tratar o tema corpo humano na sua dimensão social. Trouxemos para este artigo a análise da "experiência" de um grupo de três licenciandas, na qual as mesmas problematizavam a obesidade, em interlocução com os aspectos relacionados aos hábitos e ao consumo modernos. 
Nesta seção, trazemos as manifestações das discentes relativas ao questionamento das contribuições da experiência teatral para a formação. Assim sendo, a licencianda ANA-C. S. S. observa o seguinte:

Não tinha olhado para o teatro como uma forma de aprender a ensinar; fomos levados a aprender o conteúdo de uma forma bem diferenciada. A prática teatral contribuiu de forma significativa em minha formação, pois através dela pude aprender o conteúdo, para escrever o roteiro, pensar nas falas e para apresentá-lo precisamos ter o domínio do assunto (ANA- C. S. S.).

Corroborando com essa fala, temos Klisys (2010, p. 13) que afirma que a Ciência e a Arte (representada aqui pelo teatro) “[...] são espaços de possibilidades, investigação, autoria, autonomia, construção de conhecimentos e subjetividade”. Percebemos, então, que a discente construiu novos significados para a compreensão da relação entre ciência e arte, o que nos leva a afirmar que a "[...] função do teatro seria a de possibilitar encontros capazes de gerar novas formas de pensar, sentir, agir” (ARMILIATO; ARAUJO, 2011, p. 134).

Por sua vez, Isa- M. M. afirma que:

[...] com o passar do semestre passei a me permitir viver aquilo que os professores estavam propondo e fui entendendo que nada daquilo era em vão [...] eu precisava ter uma postura, um tom de voz, ser meio 'sem vergonha' [...].

Considerando essa abordagem, entendemos que vivenciar práticas teatrais é importante para o processo formativo, no sentido de que "[...] o professor-aprendiz tenha oportunidade de reproduzir/reconstruir essas práticas, para que ele tenha a oportunidade de refletir e quem sabe construir novas/outras maneiras de ensinar" (FREITAS, 2017, p. 130). Cabe destacar, que o objetivo da experimentação educacional não foi constituir atores, mas tão somente professores artistas, nos termos de Figueiredo (2015, p. 141), a saber: “[...] o professor artista aqui é a capacidade de o professor ser criador no espaço da sala de aula [...]”. Entendemos que é fundamental que proporcionemos situações que colaborem para tal condição, e, neste sentido, a materialidade mediadora do teatro cumpre/cumpriu este papel.

Na mesma linha, Kar- C.S. acredita que

[...] para a formação de professores é de extrema importância [o teatro], se tratando de mostrar práticas para se trabalhar em sala, para a melhor formação [...] o teatro mostra uma variedade para ser explorada [...] podendo usar a proposta do teatro como forma de sistematização do conteúdo ou como uma forma mais lúdica de se trabalhar um tema.

De fato, o teatro tem a possibilidade de ampliar o potencial educativo e formativo, para além dos meros mecanismos de reprodução do conhecimento. Segundo Guerra (2013), o processo de ensino e de aprendizagem, envolvendo o teatro, pode provocar transformações múltiplas: no aluno, no professor, no espaço da sala de aula e na escola. Podemos referir que na ambiência de sala de aula, a comunicação pode assumir formas distintas, não somente a 
perspectiva verbal, narrativa e, neste sentido, experiências teatrais levam a pensar em novos/outros modos de ensinar e de aprender ciências.

Por fim, as licenciandas manifestaram a intenção de trabalhar o teatro com os seus futuros alunos, nos seguintes termos:

[...] eu trabalharia teatro com meus alunos, pois por meio das práticas teatrais é possível aprender o conteúdo de uma maneira bem diferente, além de promover a socialização, espontaneidade, relacionamento, imaginação e o conhecer do seu próprio corpo [...] farei uso da linguagem artística para ensinar (ANA- C. S. S.);

[...] vi no teatro uma forma de trabalhar diversos conteúdos e pretendo, sim, levar para a sala essa linguagem artística (ISA- M. M.);

O teatro permite ter uma reflexão mais intensa a cerca do assunto abordado, pois ele envolve a fala, o pensamento e comportamento, fazendo com que a pessoa que o pratica ter uma visão diferenciada, vista por um ângulo, sentida de uma maneira mais tocante, em situações onde refletir seja melhor do que agir (KAR- C. S.).

Em apoio às ponderações das discentes, podemos referir que a materialidade mediadora do teatro, pode contribuir para a qualidade do ensino de ciências, e "comunicar" aos professores que o teatro pode trazer mudanças, renovação do fazer docente, entre outros aspectos (CACHAPUZ, 2014). Podemos referir ainda que, enquanto “[...] estratégia lúdica o teatro humaniza a prática, pois contempla os sentimentos, as sensações e a intuição, tanto quanto a razão" (SOARES, 2011, p. 2).

Nesse processo, podemos contemplar o abandono das narrativas (aulas expositivas), que dá lugar ao ensino centrado no aluno, que pode favorecer a discussão, a negociação de significados e apresentação de um produto, decorrente das atividades colaborativas e críticas (MOREIRA, 2011), como foi no nosso caso - a produção de esquete teatral, problematizando a obesidade. É nesse contexto, que a interlocução Ciência e Arte expressa uma visão não reducionista do conhecimento.

É necessário compreendermos que cabe a educação, em geral, e ao ensino de ciências, em particular, favorecer processos de mudanças de comportamento e de formação de atitudes que colaborem para pensar o ensino do corpo, para além das partes, inserindo-o, também, no contexto das preocupações contemporâneas do campo da saúde. Por outro lado, temos que reconhecer o seguinte:

A utilização de diferentes linguagens artísticas podem sensibilizar professores e alunos para um ensino de ciências mais criativo, ampliando a percepção do papel da ciência e da arte; desenvolvendo estratégias, processos, metodologias e produtos que aumentem a criatividade [...] praticando um ensino que estimule a imaginação, a criatividade, a sensibilidade e a intuição (FERREIRA, 2010, p. 3).

A ação teatral instiga a manifestação de novas ideias, o que, em geral, tem por base "[...] experiências com o cotidiano dos alunos que testam o lugar do novo, no aqui e agora 
numa iniciativa de ação/reflexão que encontram diversos desafios e precisam recorrer à memória, aos limites da realidade individual e de grupo" (SILVA, 2015, p. 7).

E, nesse sentido, evidencia-se o diálogo para além da intelectualidade, ou seja, no sentido de constituir "[...] outras percepções que vão além da fala e da escrita" (OCHÔA; SCHELBAUER, 2013, p. 6). Ademais, concordamos com Freitas (2017, p. 139), nos seguintes termos:

[...] o teatro possibilita inaugurar um conhecimento próprio, original e autêntico, além de promover realmente transposição, não reducionista, dos conhecimentos socialmente relevantes, cujas articulações, tensões e embricamentos podem conferir a apreensão/construção de novos/outros significados ao/do mundo.

Nesse sentido, o ensino de ciências pode considerar como possibilidade de pesquisa, como aqui o fizemos, a compreensão da relação entre a materialidade mediadora do teatro e a apreensão de conteúdos de ciências, na perspectiva de pontuar as contribuições desta relação na configuração de um ensino criativo e crítico.

\section{CONSIDERAÇÕES FINAIS}

A abordagem ao corpo humano implica considerá-lo multíplice, pois ao mesmo tempo em que é biológico é também social, para exemplificar. Ao considerar essa multiplicidade de conformações, buscamos escapar da perspectiva de ensino que o apresenta, exclusivamente em partes, sistemas, órgãos etc. (dimensão biológica), deixando em segundo plano ou mesmo se eximindo de tratá-lo sob a ótica de outras dimensões que o constituem.

Assim sendo, procuramos incorporar na experiência formativa, ora analisada, o ensino do corpo humano na sua dimensão social. Nesse contexto, recorremos à materialidade mediadora do teatro, reconhecendo que o teatro constitui-se importante estratégia de ensino. A obesidade representou o "cenário de problematização" das questões contemporâneas, relacionadas ao corpo humano e à saúde.

No esquete teatral, a figura do Seu Gordonildo, com seus hábitos e consumo obesogênicos, trouxe a cena sua opção alimentar - um sanduíche. O enredo desenvolveu-se em torno do diálogo dos seus ingredientes, em seu percurso pelo sistema digestório, com destaque as estruturas, aos órgãos, deste sistema, e aos conteúdos científicos relativos ao processo de digestão; além de referência a qualidade alimentar de alguns dos seus ingredientes. Nesse processo, foi possível perceber que as autoras do esquete teatral caminharam no sentido de uma intencionalidade crítica ao problematizar o tema obesidade e suas questões envolventes.

Nesse sentido, também, observamos que as licenciandas construíram um discurso cênico com criticidade e criatividade, no contexto do ensino de Ciências, na abordagem de um 
tema vinculado as preocupações atuais do campo da saúde, precisamente ao experimentarem um modo próprio de problematização dos aspectos associados, ao que podemos caracterizar como uma epidemia contemporânea, a obesidade. As licenciandas colocaram em evidencia o cotidiano da sociedade, associado aos tempos modernos, notadamente no que diz respeito à celeridade da vida atual na configuração de comportamentos alimentares obesogênico, afastando-se da compreensão do corpo (ser) humano desvinculado da sociedade, com todos os seus enredos circunscritos.

A experiência formativa, na nossa visão e das discentes, levou à constituição de um ambiente de criação, bem como de (re)afirmação das possibilidades do teatro como novo/outro modo de aprender e de ensinar ciências. Assim, no uso da arte (teatro) para apropriação das ciências, oportunizamos as discentes uma formação ativa, na medida em que as mesmas foram protagonistas do seu aprender, conformando-se um espaço de autonomia e de manifestação subjetiva.

O enredo formativo trouxe a cena possibilidades de pensar o ensino e o fazer docente diferenciado, na medida em que as discentes manifestaram intenção de utilização dessa linguagem artística em suas salas de aula. Nesse sentido, contribuímos para a formação ambiental, na consideração do teatro como um dos elementos necessários ao repertório de práticas docentes. Assim, deparamo-nos com a importância da experiência sensível no processo de formação de professores, ao mesmo tempo em que constituímos uma ambiência de criatividade na formação de professores que ensinam ciências.

\section{REFERÊNCIAS}

ANTUNES, J. L. F. Condições socioeconômicas em saúde: discussão de dois paradigmas. Revista de Saúde Pública, São Paulo, v. 42, n. 3, p. 562-567, 2008.

ARMILIATO, V.; ARAUJO, S. C. dos S. O lugar do político no teatro. O Mosaico. Revista de Pesquisa em Artes da Faculdade de Artes do Paraná, Curitiba, n. 5, p. 134-146, 2011.

AZAMBUJA, A. P. O; NETTO-OLIVEIRA, E. R.; OLIVEIRA, A. A. B.; AZAMBUJA, M. A.; RINALDI, W. Prevalência de sobrepeso/obesidade e nível econômico de escolares. Revista Paulista de Pediatria, São Paulo, v. 31, n. 2, p. 166-171, 2013.

BATISTA FILHO, M.; RISSIN, A. A transição nutricional no Brasil: tendências regionais e temporais. Caderno de Saúde Pública, Rio de Janeiro, v. 19, sup. 1, p. 181-191, 2003.

BAUER, R. C.; PANOSSO NETTO, A.; TRIGO, L. G. G. Slow movement: reação ao descompasso entre ritmos sociais e biológicos. Revista de Estudos Culturais, São Paulo, n. 2, p. 1-22, 2015. 
BRASIL. Ministério da Saúde. Secretaria de Atenção à Saúde. Departamento de Atenção Básica. Estratégias para o cuidado da pessoa com doença crônica: obesidade. Brasília: Ministério da Saúde, 2014. (Cadernos de Atenção Básica, n. 38).

CACHAPUZ, A. F. Arte e ciência no ensino das ciências. Interacções, Portugal, n. 31, p. 95$106,2014$.

CORSO, A. C. T.; CALDEIRA, G. V.; FIATES, G. M. R.; SCHMITZ, B. A. S.; RICARDO, V, G. D; VASCONCELOS, F. A. G. Fatores comportamentais associados ao sobrepeso e à obesidade em escolares do Estado de Santa Catarina. Revista Brasileira de Estudos de População, Rio de Janeiro, v. 29, n. 1, p.117-131, 2012.

FARIAS JÚNIOR, J. C; SILVA, K. S. Sobrepeso/obesidade em adolescentes escolares da cidade de João Pessoa - PB: prevalência e associação com fatores demográficos e socioeconômicos. Revista Brasileira de Medicina do Esporte, São Paulo, v. 14, n.2, p. 104$108,2008$.

FERNANDES, R. A.; CASONATTO, J; CHRISTOFARO, D. G. D.; RONQUE, E. R. V; OLIVEIRA, A. R.; FREITAS JÚNIOR, I. F. Riscos para o excesso de peso entre adolescentes de diferentes classes socioeconômicas. Revista da Associação Médica Brasileira, São Paulo, v. 54, n. 4, p. 334-338, 2008.

FIGUEIREDO, R. C. de. A aprendizagem da docência em teatro através da participação em um projeto de Extensão Universitária. Art Research Journal, Rio Grande do Norte, v. 2, n. 2, p. 138-153, 2015.

FERREIRA, F. R. Ciência e arte: investigações sobre identidades, diferenças e diálogos. Educação e Pesquisa, São Paulo, v. 36, n. 1, p. 261-280, 2010.

FREITAS, N. M. S. Ensino de ciências e práticas teatrais: formação de professores para os anos escolares iniciais. 2017. 210 f. Tese (Doutorado em Educação em Ciências e Matemática)s. Programa de Pós-Graduação em Educação em Ciências e Matemáticas, Universidade Federal do Pará. Pará. 2017.

FOODS INGREDIENTS BRAZIL. Dossiê: fibras alimentares. Revista FIB, São Paulo, n. 3, p. 1-24, 2008.

GALVÃO, C. Narrativas em educação. Ciência \& Educação, Bauru, v.11, n. 2, p. 327- 345, 2005.

GOMES, I. M.; Obesidade como metáfora contemporânea: uma "Cruzada Saudável” em nome do consumo e do risco. Movimento, Porto Alegre, v.12, n. 03, p. 45-71, 2006.

GUERRA, E. C. Impressões acerca do pensamento filosófico como contribuição para uma orientação teatral na Educação. Revista Educação, Artes e Inclusão, Florianópolis, v. 8, n. 2, p. 59-78, 2013.

IBGE. Pesquisa de Orçamentos Familiares 2008-2009: análise do consumo alimentar pessoal no Brasil. Rio de Janeiro: Instituto Brasileiro de Geografia e Estatística, 2011. 
Pesquisa de Orçamentos Familiares 2008-2009: antropometria e estado nutricional de crianças, adolescentes e adultos no Brasil. Rio de Janeiro: Instituto Brasileiro de Geografia e Estatística, 2010.

JEFFERY, R.W.; BAXTER, J.; MCGUIRE, M.; LINDE, J. Are fast food restaurants an environmental risk factor for obesity? International Journal of Behavioral Nutrition and Physical Activity, USA, v. 3, n. 2, 2006. Disponível em: < www.ncbi.nlm.nih.gov/ pmc/articles/PMC1397859/> .Acesso em 05/03/2008.

JOSSO, M. C. Experiências de vida e formação. $2^{\text {a }}$ ed. Natal, EDUFRN: 2010.

KLISYS, A. Ciência, arte e jogo. São Paulo: Peirópolis, 2010.

MACHADO, E. F. C, BARRETO, A. B. A concepção de corpo abordada nos livros didáticos de biologia do programa nacional do livro didático (PNDL) 2012-2014. Seminário do Programa de Pós-Graduação em Educação para Ciências e Matemática, 1; Semana de Licenciatura, 10. Jataí - Goiás, 26 a 29 de junho de 2013. Disponível em: < http://www.jatai.ifg.edu.br/semlic/seer/index.php/anais/article/view /300/pdf 51>. Acesso em: 5 jan. 2018.

MENDES, M. I. B. de S.; NÓBREGA, T. P. Corpo, natureza e cultura: contribuições para a educação. Revista Brasileira de Educação, Rio de Janeiro, n. 27, p. 125-137, 2004.

MORAES, R.; GALIAZZI, M. C. Análise textual discursiva. Ijuí: Unijuí, 2013.

MENDONÇA, C. P.; ANJOS, L. A. Aspectos das práticas alimentares e da atividade física como determinantes do crescimento do sobrepeso/obesidade no Brasil. Cadernos de Saúde Pública, Rio de Janeiro, v. 20, n. 3, p. 698-709, 2004.

MOREIRA, M. A. Abandono da narrativa, ensino centrado no aluno e aprender a aprender criticamente. Ensino, Saúde e Ambiente, Rio de Janeiro, v. 4, n. 1, p. 2-17, 2011.

MOREIRA, L. B.; VILELA, M. L.; SELLES, S. L. E. Abordagens sobre corpo humano e saúde na Educação em Ciências: levantamento em periódicos brasileiros (1996 - 2014). In: Encontro Regional de Ensino de Biologia, 3. Regional 4 SBEnBio. Universidade Federal de Juiz de Fora: Juiz de Fora, 2015. Anais ... Disponível em:

<http://www.sbenbio.org.br/blog/anais-do-encontro-regional-de-ensino-de-biologiaregional-4/>. Aceso em $10 \mathrm{dez} 2017$.

OCHÔA, P. C. de A.; SCHELBAUER, A. R. Teatro na formação de professores das séries iniciais do ensino fundamental. In: Seminário de Pesquisa do PPE. Universidade Estadual de Maringá, 12 a 14 de Junho de 2013. Disponível em: < http://www.ppe.uem.br/publicacoes/seminario_ppe_2013/trabalhos/co_03/85.pdf>. Acesso em 10 jan.2018.

OMS. ORGANIZAÇÃO MUNDIAL DA SAÚDE. Obesity: preventing and managing the global epidemic. Geneva, Switzerland: WHO, 2000. (WHO Technical Report Series, n. 894). 
OTTO, A. F. N; RIBEIRO, M. A. Unidos em torno da mesa: a dinâmica familiar na obesidade. Estudos de Psicologia, Natal, v.17, n. 2, p. 255-263, 2012.

POPKIN, B. M. Is the obesity epidemic a national security issue around the globe? Current Opinion in Endocrinology, Diabetes and Obesity, USA, v. 18, n. 5, p. 328-331, 2011.

POPKIN, B. M. O mundo está gordo: modismos, tendências, produtos e políticas que estão engordando a humanidade. São Paulo: Campus, 2008.

MOREIRA, M. A. Abandono da narrativa, ensino centrado no aluno e aprender a aprender criticamente. Ensino, Saúde e Ambiente, Rio de Janeiro, v. 4, n. 1, p. 2-17, 2011.

RAMOS, K. C. A. B.; FONSECA, L. C. S.; GALIETA, T. Visões sobre o ser humano e as práticas docentes no ensino de ciências e biologia. Revista Exitus, Santarém, Pará, v. 8, n. 1, p. 305-331, 2018.

RECH, R. R.; HALPEN, R.; COSTANZI, C. B.; MAUREN LÚCIA DE ARAÚJO BERGMANN, M. L. A.; ALLI, L. R.; MATTOS, A. P.; TRENTIN, L.; BRUM, L. R. Prevalência de obesidade em escolares de 7 a 12 anos de uma cidade Serrana do RS, Brasil. Revista Brasileira de Cineantropometria e Desempenho Humano, Florianópolis, v. 12, n. 2, p. 90-97, 2010.

RIOS, F. T. A. A importância do corpo no processo de ensino e aprendizagem. Evidência, Araxá, v. 11, n. 11, p. 49-58, 2015.

ROIZMAN, D. H. A obesidade como prato cheio para o capitalismo. A peste, São Paulo, v. 3, n. 2, p. 29-37, 2011.

SANTOS, L. H. S. dos. Incorporando outras representações culturais de corpo na sala de aula. In: OLIVEIRA, D. L. de. Ciências nas salas de aula. Porto Alegre: Mediação, 2002. p. $97-$ 112.

SILVA, A. L. R. Do ensinar e do aprender teatro: a improvisação teatral e o processo criativo na sala de aula. 2015. 29 f. Dissertação (Mestrado Profissional em Arte).

PROFARTES. Universidade Federal da Bahia. Bahia, 2015.

SOUZA, E. B de. Transição nutricional no Brasil: análise dos principais fatores. Cadernos UniFOA, Volta Redonda, Rio de Janeiro, n.3, p. 49-53, 2010.

SOUZA, P. P.; OLIVEIRA, M. R. M. O ambiente como elemento determinante da obesidade. Simbio-Logias: Revista Eletrônica de Educação, Filosofia e Nutrição, Botucatu, São Paulo, v.1, n.1, 157-173, 2008.

TALOMONI, A. C. B; BERTOLLI FILHO, C. Corpo e vida nas representações de estudantes do ensino fundamental. In: CALDEIRA, A. M. A. (Org). Ensino de ciências e matemática, II: temas sobre a formação de conceitos. São Paulo: Editora UNESP; Cultura Acadêmica, 2009. 
; __ Representações sociais do corpo humano: desafios e implicações para o ensino de ciências. Encontro Nacional de Educação em Ciências, 5, 2005. Atas ... Disponível em: < http://abrapecnet.org.br/atas_enpec/venpec/conteudo/artigos/1/pdf/ p615.pdf >. Acesso em: 05 jan.2018.

VASCONCELLOS, M. A arte entra em cena na escola. In: SILVA, A. C. Escola com arte: multicaminhos para a transformação. Porto Alegre: Mediação, 2006. p. 35-54.

VIANNAY, C. V. C.; SELLES, S. L. E. Produção acadêmica sobre o ensino do corpo humano nas disciplinas escolares ciências e biologia. Revista SBENBIO, São Paulo, n. 9, p. 3897-3907, 2016. 